\title{
Treatment Administered to Newborns With Congenital Syphilis During the Period of Penicillin Shortage in Brazil
}

Ana Fatima Braga Rocha ( $\nabla$ ana_lumen@hotmail.com )

Universidade de Fortaleza https://orcid.org/0000-0002-4937-6397

Maria Alix Leite Araújo

Universidade de Fortaleza

Melanie M. Taylor

World Health Organization Department of Sexual Reproductive Health and Research

Edna O. Kara

World Health Organization Department of Sexual Reproductive Health and Research

Nathalie Jeanne Nicole Broutet

World Organization Health Department of Sexual Reproductive Health and Research

Research article

Keywords: Penicillin, Syphilis, Congenital syphilis, Shortage, Treatment

Posted Date: July 20th, 2020

DOI: https://doi.org/10.21203/rs.3.rs-44339/v1

License: (c) (i) This work is licensed under a Creative Commons Attribution 4.0 International License.

Read Full License

Version of Record: A version of this preprint was published at BMC Pediatrics on April 8th, 2021. See the published version at https://doi.org/10.1186/s12887-021-02619-x. 


\section{Abstract \\ Background}

Between 2014 and 2016, Brazil experienced a severe shortage in penicillin supply, resulting in a lack of treatment among some pregnant women and newborns with syphilis and the use of non-evidence-based regimens. The aim of this study is to describe the different therapeutic regimens used in newborns with congenital syphilis during the period of penicillin shortage using a retrospective cross-sectional study design conducted in Fortaleza, Northeast Brazil.

\section{Methods}

Hospital medical records and case reporting forms of live births reported with congenital syphilis in 2015 and the associated maternal syphilis cases were reviewed during June 2017 to July 2018 from all public maternity hospitals in the city of Fortaleza.

\section{Results}

A total of 575 congenital syphilis cases were reported to the municipality of Fortaleza during 2015 and $469(81.5 \%)$ were analyzed. Of these, only $210(44.8 \%)$ were treated with a nationally-recommended treatment. As alternative therapeutic options, ceftriaxone was used in $65(13.8 \%)$, Cefazolin in $15(3.2 \%)$ and the combination of more than one drug in 179 (38.2\%). Newborns with VDRL titers $>1: 8(p=0.021)$, who had some clinical manifestation at birth $(p=0.003)$, who were born premature $(p<0.001)$, with low birth weight $(p=0.010)$, with jaundice indicative of the need for phototherapy $(p=0.019)$ and with hepatomegaly $(p=0.045)$ were more likely to be treated with penicillin according to national treatment guidelines compared to newborns treated with other regimens.

\section{Conclusion}

During the period of shortage of penicillin in Fortaleza, less than half of the infants with CS were treated with a nationally-recommended regimen, the remaining received treatment with medications available in the hospital of birth including drugs that are not part of nationally or internationally-recommended treatment recommendations.

\section{Background}

Identification of syphilis in pregnant women followed by treatment with benzathine penicillin can prevent adverse birth outcomes related to congenital syphilis, including stillbirth and neonatal death [1]. When a pregnant woman with syphilis is not diagnosed or treated adequately with benzathine penicillin during pregnancy, it is imperative to treat the infant with penicillin immediately following delivery with penicillin 
as some manifestations of congenital syphilis (CS) can be reversed and long-term manifestations prevented [2].

In Brazil, the vast majority of newborns with CS are treated in hospitals with crystalline or procaine penicillin for a period of ten days taking into consideration clinical and epidemiological criteria of the mother and baby. The appropriate therapeutic scheme is defined following performance of laboratory tests in newborns such as the Venereal Disease Research Laboratory (VDRL), a complete blood count, long bone radiography and a lumbar puncture for cerebrospinal fluid (CSF) testing using VDRL, protein, and white blood cell count [3].

Between 2014 and 2016, Brazil, along with 38 other countries, experienced a serious penicillin supply shortage due to manufacturing interruptions and quality assurance issues, resulting in lack of correct treatment among some pregnant women and infants with syphilis and use of non-evidence-based regimens [4]. The Ministry of Health $(\mathrm{MoH})$ recommended the prioritization of benzathine penicillin for the treatment of pregnant women with syphilis and crystalline penicillin for infants with CS. The MoH did not recommend alternative treatment regimens for treatment of syphilis among pregnant women when penicillin was not available. The alternative treatment regimen recommended for infants during the period of penicillin shortages included ceftriaxone 25 a $50 \mathrm{mg} / \mathrm{kg}$, once a day, intravenously or intramuscularly for 10 to 14 days [5]. Alternative treatments for infants were also proposed, even with no scientific evidence showing their effectiveness, reinforcing the need for strict monitoring of all children treated with these schemes [5]. However, other treatment regimens to replace penicillin were also widely used. Large-scale studies assessing the efficacy of these alternative treatments for penicillin among infants with CS are not available.

Estimates by the World Health Organization (WHO) showed that, in 2016 globally, around 1 million pregnant women were infected with syphilis resulting in over 600,000 CS cases of which 355,000 were adverse birth outcomes including 200,000 stillbirths and neonatal deaths. The incidence rate of CS has minimally declined between 2012 and 2016. Missed opportunities for prevention, specifically related to testing and treatment during pregnancy, account for the majority of estimated CS cases globally [6].

According to the Pan American Health Organization (PAHO), in 2015, more than 22,800 cases of CS were recorded in countries in Latin America and the Caribbean, corresponding to an incidence rate of 1.7 cases per thousand live births (PAHO, 2016). This rate is mainly related to the cases notified by Brazil, which corresponded to $85 \%$ of the records in this region [7].

In Brazil, CS is a mandatory notification event and recent epidemiological data indicate an incidence rate of 9.0 cases per thousand live births, with the Northeast Region representing a higher rate $(9,6$ per thousand live births) as compared to national rates [8]. These rates are much higher than the elimination threshold established by the WHO, which is less than 0.5 cases for every thousand live births [9] showing that effective prevention measures in general and high-risk populations need to be implemented for this goal to be achieved in Brazil. 
Fortaleza has a population of approximately 2.5 million inhabitants whose health care is offered through the Unified Health System (SUS), which has a network of services with different levels of complexity.

Maternal syphilis rates are high in Fortaleza and CS is a serious problem with detection rate of 23.1 cases per thousand live births [10], much higher than the national incidence rate [8]. Fortaleza experienced stockouts of penicillin during 2014-2016.

The aim of this study is to identify the different therapeutic regimens used in newborns with CS during the period of penicillin shortage using a retrospective cross-sectional study design conducted in the capital city of Fortaleza, State of Ceará, Northeast Brazil.

\section{Methods}

Medical chart review of maternal and infant cases was conducted for the time period June 2017 to July 2018 and was carried out in all public maternity hospitals in the city of Fortaleza, which attends an average of 39,000 births a year and is responsible for $99.4 \%$ of the municipality's CS notifications.

The study included all live births notified with CS in 2015, the period during which Fortaleza experienced shortage of penicillin. Antenatal care clinics and obstetrics units experienced different shortage scenarios varying from total stockout to insufficient quantity of penicillin formulations (benzathine, procaine, crystalline) to supply the demand for treatment of pregnant women and newborns.

For this study, the following MoH CS definition was used [3]:

- Live born infant whose mother presents, during prenatal care or at the time of delivery, with a reactive non-treponemal test with any titration and reactive treponemal test, and who has not been treated or has received inadequate treatment.

- - Live born infant whose mother was not diagnosed with syphilis during pregnancy and has a positive non-treponemal test of any titration at the time of delivery.

- - Live born infant whose mother was not diagnosed with syphilis during pregnancy and has a positive treponemal test at the time of delivery.

- - Live born infant whose mother has a positive treponemal test and a non-treponemal non-reactive test (of any titration) at the time of delivery, without prior treatment.

According to Brazil MoH guidelines [3], newborns with CS should be treated as follows:

1) Newborns without clinical signs of CS at birth with a non-reactive VDRL, should receive benzathine penicillin $\mathrm{G}$, a single dose of 50,000 IU/kg intramuscularly.

2) Newborns with abnormal cerebrospinal fluid (CSF) (positive CSF VDRL, elevated protein) should receive crystalline penicillin $\mathrm{G} 50,000 \mathrm{IU} / \mathrm{kg} /$ dose, intravenously, every 12 hours (in the first 7 days of life) and every 8 hours (after 7 days of life), for 10 days. 
3) Newborns with clinical evidence of congenital syphilis including positive VDRL, abnormal long bone $x$ rays, and/or physical findings consistent with CS should receive crystalline penicillin $\mathrm{G}$ $50,000 \mathrm{lU} / \mathrm{kg} /$ dose, intravenously, every 12 hours (in the first 7 days of life) and every 8 hours (after 7 days of life), for 10 days; or penicillin $\mathrm{G}$ procaine $50,000 \mathrm{IU} / \mathrm{kg}$, single daily dose, intramuscularly for 10 days.

CS case notification forms and hospital medical records were reviewed to collect information on infant diagnosis and treatment. When there were inconsistencies between the records, the data in the medical record was used.

In the analysis of infant treatment outcomes, cases of newborns who died, non-residents in the city of Fortaleza and infant cases whose medical records were not found were excluded. Cases who had coinfection with HIV, hepatitis B and C, toxoplasmosis, rubella, cytomegalovirus, congenital herpes virus or zika virus were also excluded due to the possibility of interference in the evaluation of the clinical manifestations and laboratory findings of CS.

The variables analyzed were: timing of mother's diagnosis, mother's treatment during prenatal care, gestational age at delivery, baby's weight at birth, performance and result of the non-treponemal test (VDRL) of peripheral blood and CSF, presence of CSF abnormalities, radiological examination of long bones, changes in the complete blood count (CBC), presence of clinical manifestations of CS at birth, and treatment regimen administered to the newborn.

The nationally-recommended treatment scheme for CS comprised any of the three options: 1) crystalline penicillin $\mathrm{G} 50,000 \mathrm{IU} / \mathrm{kg} /$ dose, intravenously, every 12 hours (in the first 7 days of life) and every 8 hours (after 7 days of life), for 10 days; 2) penicillin $\mathrm{G}$ procaine $50,000 \mathrm{lU} / \mathrm{kg}$, single daily dose, intramuscularly for 10 days; 3) benzathine penicillin $\mathrm{G}$, a single dose of $50,000 \mathrm{IU} / \mathrm{kg}$ intramuscularly. Treatments that followed the national guideline regimens for CS, including clinical and laboratorial parameters of mothers and infants, were considered adequate [3].

Newborn exams were considered abnormal based on the following parameters: CSF- result of reagent VDRL, proteins $>150 \mathrm{mg} / \mathrm{dL}$ and / or leukocytes $>25 \mathrm{cells} / \mathrm{mm} 3$; Radiography of long bones - presence of involvement in the metaphysis or diaphysis or findings consistent with periostitis, osteitis or osteochondritis; $\mathrm{CBC}$ - anemia (hemoglobin - 1 to 3 days of life: 14.5 to $22.5 \mathrm{~g} / \mathrm{dL}, 7$ days of life: 13.5 to $21.5 \mathrm{~g} / \mathrm{dL}$ ), thrombocytopenia (newborn: $<300.000$ to $600.000 / \mathrm{mm} 3,2$ to 7 days of life: 250.000 to $550.000 / \mathrm{mm} 3$ ), leukocytosis and leukopenia (reference values for leukocytes: up to 1 day of life: 9000 to $30000 / \mathrm{mm} 3,2$ to 7 days of life: 5000 to $21000 / \mathrm{mm} 3$; reference values for neutrophils: up to 1 day of life: 6000 to $26000 / \mathrm{mm} 3,2$ to 7 days of life: 1500 to $10000 / \mathrm{mm} 3$ ) [11].

Clinical manifestations at birth were those related to early CS: prematurity (birth with gestational age less than 37 weeks), low birth weight (<2,500 grams), hepatomegaly, splenomegaly, skin lesions, jaundice consistent with need for phototherapy and pseudoparalysis of the limbs [3]. 
The data were analyzed using the statistical software SPSS (Statistical Package for the Social Sciences) version 22. A descriptive analysis was performed using the frequency distribution for the categorical variables and bivariate analysis that applied Pearson's $\chi 2$ test and Fisher's exact test, establishing a 5\% significance level and a 95\% confidence interval.

This study was approved by the Research Ethics Committee of the University of Fortaleza (UNIFOR) with opinion number 2.110.189.

\section{Results}

In 2015, 575 live births with CS were reported in Fortaleza. Of these, 106 (18.4\%) cases were excluded from the analysis: nine cases of neonatal death, 26 not residing in Fortaleza, 43 whose medical records were not available and 28 which had co-infection. Records from the remaining 469 newborns were analyzed.

Data on the mothers of these newborns revealed that 390 (83.1\%) attended prenatal care. Of these women, $264(67.7 \%)$ were diagnosed with syphilis during prenatal care; 79 (16.9\%) women did not attend prenatal care and were diagnosed with syphilis at the time of delivery. All women were considered inadequately treated or did not undergo treatment (Table 1). 
Table 1

Maternal treatment, performed tests and clinical manifestations in cases of CS. Fortaleza, Ceará, 2015. ( $n=469)$

\begin{tabular}{|c|c|c|}
\hline Variables & $\mathbf{n}$ & $\%$ \\
\hline \multicolumn{3}{|l|}{ Maternal } \\
\hline Mother did not attend prenatal care & 79 & 16.9 \\
\hline Mother attended prenatal care & 390 & 83.1 \\
\hline Mother not diagnosed with syphilis in prenatal care & 126 & 32.3 \\
\hline Mother diagnosed with syphilis in prenatal care & 264 & 67.7 \\
\hline \multicolumn{3}{|l|}{ Maternal treatment in prenatal care } \\
\hline Inadequate treatment & 204 & 77.3 \\
\hline Untreated & 60 & 22.7 \\
\hline \multicolumn{3}{|l|}{ Newborn } \\
\hline Newborns with reactive VDRL result at birth $(n=467)^{a}$ & 367 & 78.6 \\
\hline Newborns with VDRL titration at birth $\geq 1: 16(n=367)$ & 53 & 14.4 \\
\hline CSF alteration $(n=292)^{a}$ & 26 & 8.9 \\
\hline Alteration in long bone radiography $(n=139)^{a}$ & 10 & 7.2 \\
\hline Blood count alteration $(n=362)^{a}$ & 159 & 43.9 \\
\hline Showed some clinical manifestation $(n=456)$ & 199 & 43.6 \\
\hline \multicolumn{3}{|l|}{ Type of clinical manifestation $(n=199)^{b}$} \\
\hline Jaundice level requiring phototherapy & 116 & 58.3 \\
\hline Low birth weight & 87 & 43.7 \\
\hline Preterm birth & 65 & 32.6 \\
\hline Hepatomegaly & 14 & 7.0 \\
\hline Skin lesions & 10 & 5.0 \\
\hline Splenomegaly & 8 & 4.0 \\
\hline Limb pseudoparalysis & 1 & 0.5 \\
\hline \multicolumn{3}{|c|}{ a Data available for newborns who underwent the examination. } \\
\hline b Some newborns had more than one clinic & ר. & \\
\hline
\end{tabular}


The result of the newborn's serum VDRL test was positive in 367 (78.6\%) and for $53(14.4 \%)$ the titration was $\geq 1: 16$. A total of $26(8.9 \%), 10(7.2 \%)$ and $159(43.9 \%)$ infants had alterations at the CSF exam, in the long-bone radiography and in the blood count, respectively. Four hundred and fifty-six $(97.2 \%)$ newborns had a physical examination recorded in their medical files and 199 (43.6\%) showed signs and symptoms of CS (Table 1).

In order to identify the administration of appropriate treatment, the 469 newborns in this study were analyzed based on the recommendations of the $\mathrm{MoH}$ for treatment of CS which considers the criteria of: maternal treatment, presence of signs and symptoms and laboratory and radiographic evaluation of the newborns [3]. Only 210 (44.8\%) infants were treated with a nationally-recommended scheme. Of the 47 children who should have received a single dose of benzathine penicillin, 40 (85.1\%) were hospitalized for 10 days and treated with other intravenous regimens (Fig. 1).

As alternative therapeutic options, ceftriaxone was used in 65 (13.8\%) newborns, Cefazolin in 15 (3.2\%) and the combination of more than one drug in 179 (38.2\%) (Table 2).

Table 2

Treatments administered to CS during the penicillin shortage period. Fortaleza, Ceará. 2015. N = 469.

\begin{tabular}{|lll|}
\hline Newborns' treatment & $\mathbf{n}$ & $\%$ \\
\hline Standard scheme & & \\
\hline Crystalline Penicillin 10 days & 187 & 39.9 \\
\hline Penicillin Procaine 10 days & 16 & 3.4 \\
\hline Benzathine penicillin, single dose & 7 & 1.5 \\
\hline Total & 210 & $\mathbf{4 4 . 8}$ \\
\hline Other schemes & & \\
\hline Ceftriaxone 10 days & 65 & 13.8 \\
\hline Cefazolin 10 days & 15 & 3.2 \\
\hline Combination of more than one drug & 179 & 38.2 \\
\hline Total & $\mathbf{2 5 9}$ & $\mathbf{5 5 . 2}$ \\
\hline
\end{tabular}

Multi-drug treatment regimens were used to treat 179 (38.2\%) newborns. A majority, 159 (88.8\%), received crystalline penicillin as the starting drug for treatment. Each combination presented corresponds to a 10day treatment schedule. (Table 3). 
Table 3

Other treatment schemes administered to CS combining drugs. Fortaleza, Ceará, 2015. $N=179$.

\begin{tabular}{|c|c|c|c|}
\hline Initial drug & Complementary drug (s) & $\mathrm{n}$ & $\%$ \\
\hline \multirow[t]{7}{*}{ Crystalline Penicillin } & + Procaine Penicillin & 134 & 74.9 \\
\hline & + Procaine Penicillin + Crystalline Penicillin & 6 & 3.3 \\
\hline & + Benzathine Penicillin & 8 & 4.5 \\
\hline & + Ceftriaxone & 3 & 1.7 \\
\hline & + Procaine Penicillin + Benzathine & 2 & 1.1 \\
\hline & + Ceftriaxone + Procaine Penicillin & 4 & 2.2 \\
\hline & + Cephalothin + Procaine Penicillin & 2 & 1.1 \\
\hline \multirow[t]{2}{*}{ Ceftriaxone } & + Procaine Penicillin & 17 & 9.5 \\
\hline & + Crystalline Penicillin + Procaine Penicillin & 3 & 1.7 \\
\hline
\end{tabular}

Infants with VDRL titers $\geq 1: 16(p=0.021)$, who had some clinical manifestation at birth $(p=0.003)$, who were born premature $(p<0.001)$, with low birth weight $(0.010)$, with jaundice with phototherapy level $(p=$ $0.019)$ and with hepatomegaly $(p=0.045)$ were more likely to be treated with a nationally-recommended penicillin-based regimen (Table 4). 
Table 4

Alterations identified at birth in newborns with CS by treatment scheme, Fortaleza, Ceará, 2015.

\section{Variables}

Newborn Treatment

$\mathrm{p}$ value

\section{Standard scheme* Other schemes}

$\begin{array}{llll}\mathrm{n} & \mathrm{n} & \mathrm{n}\end{array}$

VDRL result $(n=467)$

Reactive

Non-reactive

VDRL titration $(n=367)$

$\leq 1: 8$

136

168

45.8

42

42.0

199

54.2

$\geq 1: 16$

32

43.3

60.4

58

58.0

0.501

CSF alteration $(n=292)$

Yes

13

97

50.0

13

50.0

No

Long bone radiography alteration $(n=139)$

Yes

3

36.5

169

178

56.7

$21 \quad 39.6$

0.021

No

46

30.0

35.7

7

70.0

Hemogram alteration $(n=362)$

Yes

61

61

38.4

93

45.8

83

64.3

No

Showed clinical manifestation at birth $(n=456)$

Yes

105

100

52.8

94

47.2

No

38.9

157

61.1

Preterm birth $(n=469)$

Yes

43

168

No

Low birth weight $(n=469)$

0.010

\footnotetext{
a Fisher's Exact test

*MoH-recommended treatment scheme
} 


\begin{tabular}{|c|c|c|c|c|c|}
\hline \multirow[t]{3}{*}{ Variables } & \multicolumn{4}{|c|}{ Newborn Treatment } & \multirow[t]{3}{*}{$\mathrm{p}$ value } \\
\hline & \multicolumn{2}{|c|}{ Standard scheme* } & \multicolumn{2}{|c|}{ Other schemes } & \\
\hline & $\mathbf{n}$ & $\%$ & $\mathbf{n}$ & $\%$ & \\
\hline Yes & 50 & 57.5 & 37 & 42.5 & \\
\hline No & 161 & 42.1 & 221 & 57.9 & \\
\hline Jaundice with phototherapy $(n=454)$ & & & & & 0.019 \\
\hline Yes & 63 & 54.3 & 53 & 45.7 & \\
\hline No & 141 & 41.7 & 197 & 58.3 & \\
\hline Hepatomegaly $(n=456)$ & & & & & 0.045 \\
\hline Yes & 10 & 71.4 & 4 & 28.6 & \\
\hline No & 196 & 44.3 & 246 & 55.7 & \\
\hline Splenomegaly $(n=456)$ & & & & & $0.477^{a}$ \\
\hline Yes & 5 & 62.5 & 3 & 37.5 & \\
\hline No & 201 & 44.9 & 247 & 55.1 & \\
\hline Skin lesions $(n=456)$ & & & & & $0.353^{a}$ \\
\hline Yes & 6 & 60.0 & 4 & 40.0 & \\
\hline No & 195 & 44.3 & 245 & 55.7 & \\
\hline${ }^{a}$ Fisher's Exact test & & & & & \\
\hline *MoH-recommended treatment scheme & & & & & \\
\hline
\end{tabular}

\section{Discussion}

The shortage of penicillin experienced in Brazil between 2014 and 2016 had an unprecedented impact on the number of pregnant women infected with syphilis who did not receive treatment or were improperly treated, resulting in large numbers of infants born with CS. Even in the face of a shortage of penicillin, all newborns received some type of treatment. In the setting of limited or no availability of penicillin and unknown effectiveness of other medications used, professionals treated more than half of the newborns with other therapeutic schemes.

Due to shortages of benzathine penicillin, prolonged hospitalizations and excessive use of antibiotics were identified for the vast majority of the newborns of this study who should have received a single dose of benzathine penicillin, making them susceptible to developing adverse reactions, hospital acquired 
infections, and other complications of hospitalization $[12,13]$. Unnecessary hospitalizations also compromised the scarce neonatal beds and increase the costs for the health system.

Other studies $[14,15]$ carried out in Brazil during periods when penicillin was available, identified a high proportion of CS cases treated according the nationally-recommended algorithm indicating provider adherence to national treatment guidelines.

During 2012 and 2013, prior to the penicillin shortages, Fortaleza had 612 and 663 live births notified with CS and $90,9 \%$ and $92,6 \%$ respectively were treated with $\mathrm{MOH}$ - recommended regimens composed of crystalline, procaine or benzathine penicillin. Of the remainder of cases $8.4 \%$ (2012) and $6.8 \%$ (2013) had no treatment reported. Only 4 cases in 2012 and 5 cases in 2013 were treated with non $\mathrm{MoH}$ recommended treatment regimens (Unpublished data provided by Fortaleza Health Secretary) compared with $210(44.7 \%)$ in 2015.

The $\mathrm{MoH}$ information note describing alternative treatment for CS was published in October 2015, about a year after the shortages began in Fortaleza. This note recommended the use of ceftriaxone for infants with CS in the event of unavailability of penicillin [5]. Therefore, for children born in the period prior to the publication of this note, the choice of treatment was at the discretion of the professionals and the drugs available in the services. This may explain some findings of this study, such as the use of cefazolin and the combination of different drugs.

Analysis of treatment outcomes among infants reported with CS was not put in place at the time of the penicillin shortages. For this reason, consistent monitoring and follow-up of these children is not available despite it being essential to assess the treatment efficacy of these alternative regimens in the medium and long terms, as well as the need for possible retreatment [5].

Although the majority of newborns reported with CS were born without obvious clinical signs, it is possible that they may present early and/or late manifestations of CS if the treatment given was inadequate $[14,16-18]$. Review of clinical follow-up of these infants is needed to assess the effectiveness of these alternative regimens and can be considered for further study.

In view of the penicillin crisis, neonatologists may have tried to ration the few doses available in the services and prioritize these doses for use in infants with clinical and laboratory abnormalities, demonstrated by the greater use of standard regimens among these infants. In this sample, infants with abnormal CSF, long bone radiography and abnormal blood count findings were not more likely to receive a standard regimen. Though this seems contradictory to provider rationing of penicillin for severe CS cases, these exams are complex procedures within these facilities possibly resulting in delays in access to the results. Physicians may have chosen to treat infants with standard regimens who had obvious clinical manifestations or changes in other tests that were more immediately available.

There are several limitations to this study which demonstrate the missed opportunity to more robustly evaluate the outcomes of treatment regimens among pregnant women with syphilis and infants with 
congenital syphilis during this period of penicillin shortages. First, as some medical records could not be located, to maximize collection of available data, the authors reviewed data from different data sources including CS case notification forms in addition to medical records. Second, large amounts of data were missing and clinical parameters were not evaluated consistently or not available for all infants, thus comparative analysis was limited. It should be noted that no other publications were identified in the peerreviewed literature whereby data on the use of alternative treatment regimens among newborns with CS were evaluated during a period of penicillin shortages. This made it impossible to compare the results to those of similar cases and settings.

There is ongoing concern related to newborns infected with CS in Brazil during 2014-2016 who received other treatment regimens for which clinical efficacy data are not available. Follow-up of infants with abnormal clinical and laboratory exam findings at the time of birth is needed and can still be performed using non-treponemal and treponemal testing even though these children now range from 4-5 years of age (as of 2020). Among adequately treated infants and children, non-treponemal results should revert to negative and treponemal tests may remain positive $[9,17]$. It is important to carry out studies that assess the possible clinical and developmental repercussions of alternative treatment regimens among these children diagnosed and treated for CS. Considering the possibility of recurrence of the shortage of penicillin [19], research that evaluates efficacy of alternative drugs for the treatment syphilis in pregnant women and CS are essential to face this problem.

\section{Conclusion}

These results demonstrate that in the period of scarcity of penicillin, in Fortaleza, the proportion of newborns reported with CS who were adequately treated was low. Different therapeutic schemes were defined and administered based on their availability in the services, including drugs that are not part of the $\mathrm{MoH}$ protocols. The data in this study warn of the need to monitor these children in order to detect and treat complications from possible inadequately treated CS and to identify and evaluate alternative treatment regimens in advance of future penicillin shortages.

\section{Abbreviations}

$\mathrm{CBC}$

Complete Blood Count

CS

Congenital Syphilis

CSF

cerebrospinal fluid

$\mathrm{MoH}$

Ministry of Health

NB

Newborns 
$\mathrm{PAHO}$

Pan American Health Organization

SUS

Unified Health System (Sistema Único de Saúde)

VDRL

Venereal Disease Research Laboratory

$\mathrm{WHO}$

World Health Organization

\section{Declarations}

\section{Ethics approval and consent to participate}

The study was approved by the Research Ethics Committee of the University of Fortaleza under No. 2.110.189.

\section{Consent for publication}

Not applicable

\section{Availability of data and material}

\section{Competing interests}

The authors declare that they have no competing interests

\section{Funding}

Not applicable

\section{Authors' contributions}

AFBR and MALAmade substantial contributions to the study's conception and design. AFBR carried out data collection. AFBR, MALA, MMT, EOK e NJNB analyzed the data, prepared the first draft of the manuscript and were involved in revising it critically for important intellectual content. All authors read and approved the final manuscript.

\section{Acknowledgements}

Fortaleza Health Secretary for providing the unpublished CS datas.

The author AFBR would like to thank FATENE (Faculdade Terra Nordeste) for granting a scholarship to carry out the research. 


\section{References}

1. Blencowe H, Cousens S, Kamb M, Berman S, Lawn JE. Lives Saved Tool supplement detection and treatment of syphilis in pregnancy to reduce syphilis related stillbirths and neonatal mortality. BMC Public Health. 2011 Apr 13;11 Suppl 3:S9.

2. World Health Organization. WHO guidelines for the treatment of Treponema pallidum (syphilis). Geneva: World Health Organization; 2016.

3. Ministry of Health (BR). Clinical Protocol and Therapeutic Guidelines for Integral Care to People with Sexually Transmitted Infections. Brasília: Ministry of Health; 2015.

4. Nurse-Findlay S, Taylor MM, Savage M, Mello MB, Saliyou S, Lavayen M, Seghers F, Campbell ML, Françoise Birgirimana F, Ouedraogo L, Pyne-Mercier L. Supply, Demand, and Shortages of Benzathine Penicillin for Treatment of Syphilis: A Market Assessment. PLoS Medicine. 2017;14(12):e1002473.

5. Ministry of Health (BR). Nota Informativa Conjunta. Nº109/2015/GAB/SVS/MS, GAB/SCTIE/MS. Orienta a respeito da priorização da penicilina benzatina para sífilis em gestantes e penicilina cristalina para síflis congênita no país e alternativas para o tratamento da sífilis [It advises on the prioritization of benzathine penicillin for syphilis in pregnant women and crystalline penicillin for congenital syphilis in the country and alternatives for the treatment of syphilis]. Brasília: Ministry of Health; 2015.

6. Korenromp EL, Rowley J, Alonso M, Brito de Mello M, Wijesooriya NS, Mahiané SG, Ishikawa N, Le LV, Newman-Owiredu M, Nagelkerke N, Newman L, Kamb M, Broutet N, Taylor MM. Global burden of maternal and congenital syphilis and associated adverse birth outcomes - estimates for 2016 and progress since 2012. PLOS One. 2019;14(2):e0211720.

7. Organización Panamericana de la Salud. Eliminación de la transmisión maternoinfantil del VIH y la sífilis en las Américas. Actualización 2016. Washington, DC: OPS; 2017.

8. Ministry of Health (BR). Boletim Epidemiológico Sífilis [Epidemiological Bulletin Syphilis]. Brasília: Ministry of Health; 2019.

9. World Health Organization. Global guidance on criteria and processes for validation: elimination of mother-to-child transmission of HIV and syphilis. 2nd edition. Geneva: World Health Organization; 2017.

10. Secretaria da Saúde do Estado do Ceará. Boletim Epidemiológico de Síflis [Epidemiological Bulletin of Syphilis]. Fortaleza, CE; 2019.

11. Lee GR, Bithell TC, Foerster J, Athens JW, Lukens JN. Wintrobe Hematologia Clínica. 9th edition. Manole, 1998.

12. Patel SJ, Saiman L. Antibiotic resistance in neonatal intensive care unit pathogens: mechanisms, clinical impact, and prevention including antibiotic stewardship. Clin Perinatol. 2010;37(3):547-63.

13. Ministry of Health (BR). Pediatria: prevenção e controle de infecção hospitalar [Pediatrics Manual Hospital Infection Prevention and Control]. Brasília: Ministry of Health; 2006. 
14. Feliz MC, Medeiros ARP, Rossoni AM, Tahnus T, Pereira AMVB, Rodrigues C. Adherence to the followup of the newborn exposed to syphilis and factors associated with loss to follow-up. Rev bras epidemiol. 2016;19(4):727-39.

15. Magalhães DMS, Kawaguchi IAL, Dias A, Calderon IMP. Sífilis materna e congênita: ainda um desafio [Maternal and congenital syphilis: a persistent challenge]. Cad Saúde Pública. 2013;29(6):1109-20.

16. Lafetá KRG, Martelli Júnior H, Silveira MF, Paranaíba LMR. Maternal and congenital syphilis, underreported and difficult to control. Rev bras epidemiol. 2016;19(1):63-74.

17. Lago EG, Vaccari A, Fiori RM. Clinical features and follow-up of congenital syphilis. Sex Transm Dis. 2013;40(2):85-94.

18. Cavalcante ANM, Araújo MAL, Nobre MA, Almeida RLF. Fatores associados ao seguimento não adequado de crianças com síflis congênita. Rev Saúde Pública. 2019;53:95.

19. Taylor MM, Nurse-Findlay S, Zhang X, Hedman L, Kamb ML, Broutet N, et al. Estimating benzathine penicillin need for the treatment of pregnant women diagnosed with syphilis during antenatal care in high-morbidity countries. PLoS One. 2016;11(7):e0159483.

\section{Figures}




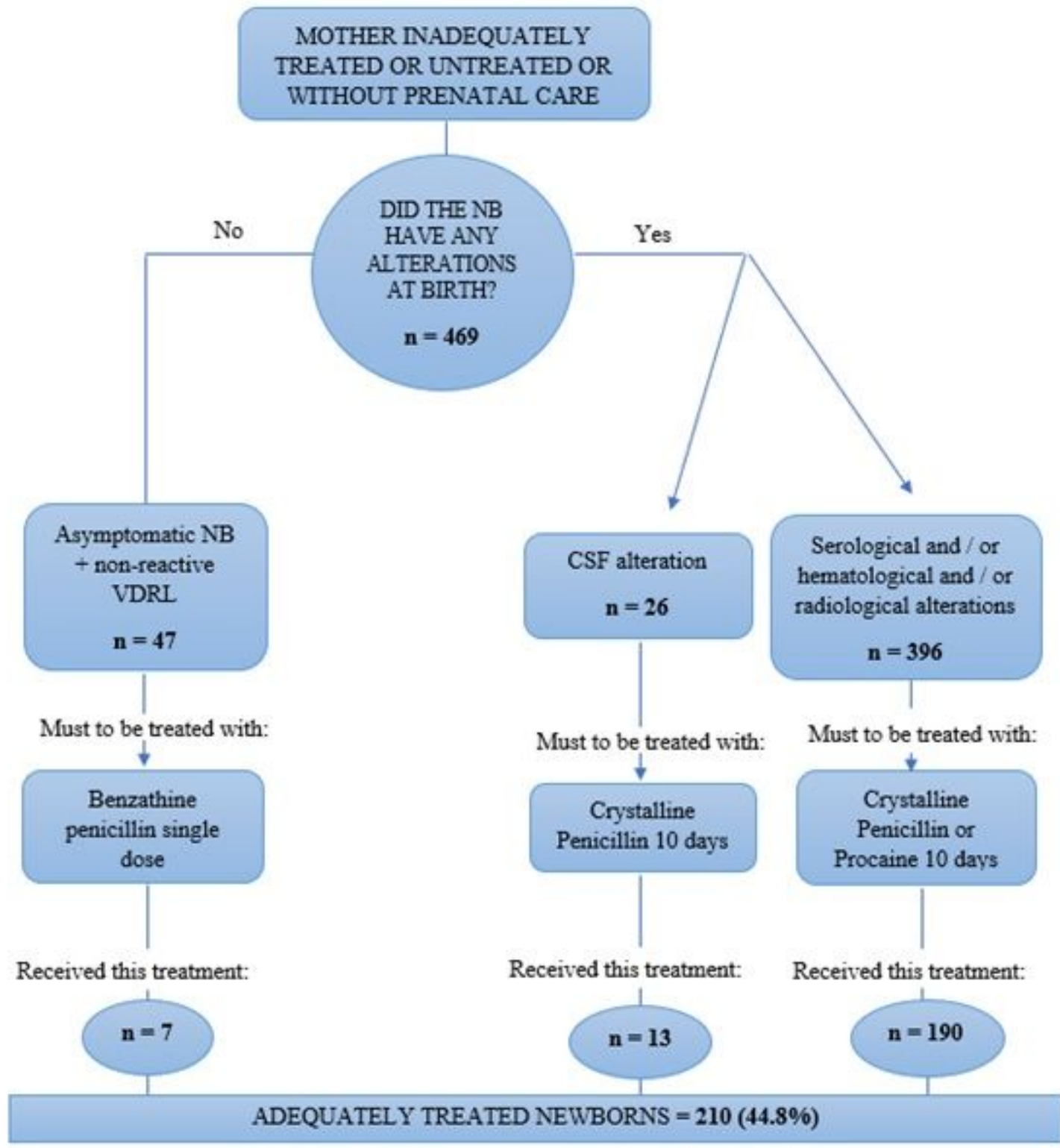

\section{Figure 1}

Algorithm for adequate treatment to of newborns (NB) with CS. Fortaleza, Ceará, 2015. Source: adapted from: Ministry of Health (BR). Clinical Protocol and Therapeutic Guidelines for Integral Care to People with Sexually Transmitted Infections. Brasília: Ministry of Health; 2015. 